\title{
Air-side pressure drop of polymeric hollow fibre heat exchangers
}

\author{
Tereza Kroulíková ${ }^{1, *}$, Ilya Astrouski ${ }^{1}$, Tereza Kůdelová ${ }^{1}$ \\ 1 Heat Transfer and Fluid Flow Laboratory, Faculty of Mechanical Engineering, Brno University of Tecnology, Technická 2, Brno, 61669
}

\begin{abstract}
Polymeric hollow fibre heat exchangers are an alternative to common metal heat exchangers in low-temperature applications. Their advantages are low cost, low weight, and corrosion resistance. The heat transfer surface consists of hundreds or even thousands of fibres of small diameter. There are several studies on thermal performance of the polymeric hollow fibre heat exchangers, but the pressure drop is also a crucial part of the design. The arrangement, known as the bank of tubes, is common for the heat exchangers and there are relations used to estimate the pressure drop of flow passing the bank of tubes. Those are based on extensive experimental research with steel tubes. The tubes of polymeric hollow fibre are flexible. The pressure drop predicted by the known relations are underestimated.
\end{abstract}

Keywords: Polymeric hollow fibre, Heat exchanger, Bank of tubes, Pressure drop.

\section{Introduction}

Polymeric hollow fibre heat exchangers (PHFHE) are heat exchangers consisted of hundreds of tiny tubes, so-called hollow fibres. The typical outer diameter of hollow fibres is in range $0.6-1.6 \mathrm{~mm}$. The thermal conductivity of polymers is low, but this can be overcome by using hollow fibres with a wall thickness of less than 100um [1]. Polymeric hollow fibre heat exchangers appear firstly in [2] and were tested for waterwater and ethanol-water systems. Then studies focusing on application in desalination appeared. Study [3] tested three different kinds of polymeric hollow fibres in hot brine-water and steam-tap water systems and proved that those devices are suitable for desalination. Another study [4] studied polymer hollow fibre heat exchanger from PVDF. In addition to corrosion resistance, polymer hollow fibre exchangers allow easy shaping and machining. They have a low weight and their cost is lower than metal units. They are also environmentally friendly since the energy required to produce a unit of mass of plastic is about 2 times less than a unit of metal [2].

To have a large active heat transfer surface the separation of fibres is needed. Otherwise, fibres can block each other, and the heat transfer surface would be inefficient. In [5] the separation of fibres in shell'n'tube hollow fibre heat exchanger was provided by the net. In comparison to the PHFHE without the net the overall heat transfer coefficient is about $30 \%$ higher. The other method of separation was presented in [6]. Each fibre is formed by stretching and thermal fixation, then each fibre has its own shape. This process is called chaotization. The chaotized bundles can achieve twice as much heat transfer rate for the same parameters of flows and fibres. Those bundles are still very flexible and can bend in various shapes. The chaotized PHFHE can be used easily for natural convection, for example as an immersed heat exchanger [7].

In 2016 rectangular shape PHFHE for the gas-liquid application was presented in two studies [8], [9]. Those PHFHE have the heat transfer surface separated by textile 
interweaving. In the study [9] two PHFHE were compared to the conventional aluminium car radiator. The values of the heat transfer coefficient were similar, but the pressure drop was higher in case of PHFHE.

The pressure drop is an important part of the designing of a heat exchanger. The previous studies focus on the heat transfer rate and its prediction. Unfortunately, there is a very few studies on the topic of pressure drop and none on the gas side in case of gas-liquid application.

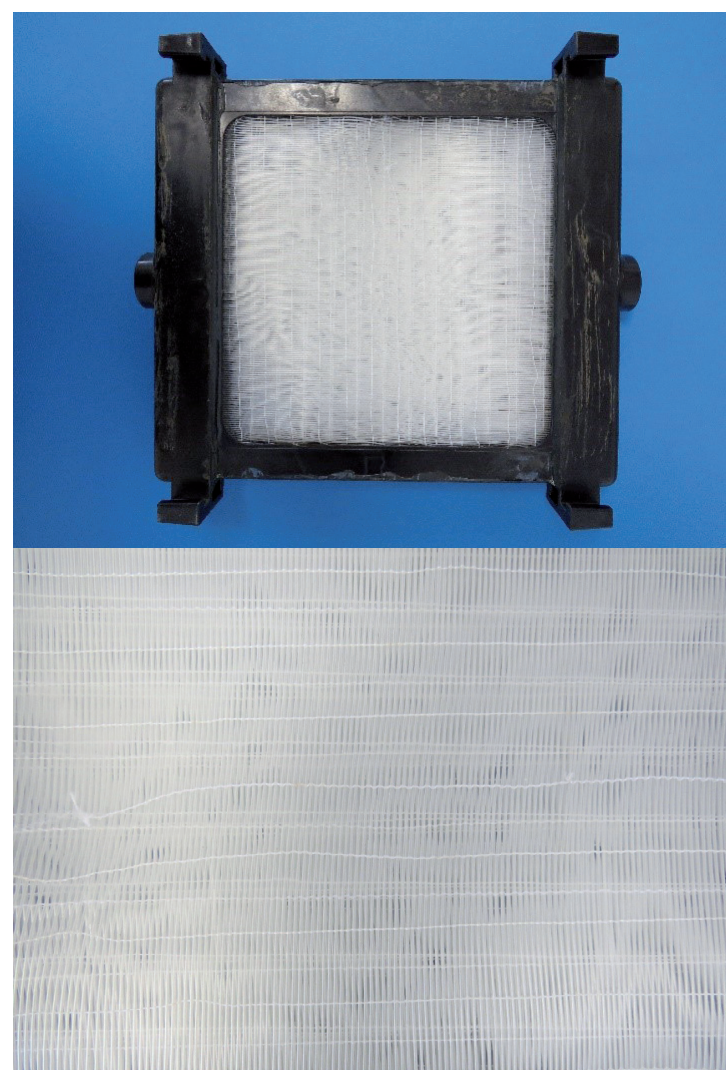

Figure 1: Polymeric hollow fibre heat exchanger with woven heat transfer surface, on the right detail.

\section{Pressure drop of a bank of tubes}

The pressure drop is defined as a difference of the total pressure between the two points of the conduit. This difference is caused by the change of mechanical work to heat [10]. The values of pressure drop depend on the geometry of the heat exchanger as well as on the heat transfer fluid and its velocity. Bank of tubes is a very common type of geometry since is widespread in most common heat exchanger type, shell and tube. In the past several empirical models for pressure drop of bank of tubes was created. In the majority of those models, the pressure drop is stated as a function of velocity of the stream, density of fluid, geometry and arrangement of tubes and pressure drop coefficient, which depends on the tube parameters and Reynolds number. There are two basic tube arrangements, in-line and staggered, see Fig. 2. The arrangements are characterized by transversal $\left(S_{T}\right)$, longitudinal $\left(S_{L}\right)$ and diagonal $\left(S_{D}\right)$ pitch but in the models, they are in form of non-dimensional pitches or pitch ratios:

$$
\begin{aligned}
& a=\frac{S_{T}}{d_{o}}, \\
& b=\frac{S_{L}}{d_{o}}, \\
& c=\frac{S_{D}}{d_{o}} \sqrt{\left(\frac{a}{2}\right)^{2}+b^{2}} .
\end{aligned}
$$
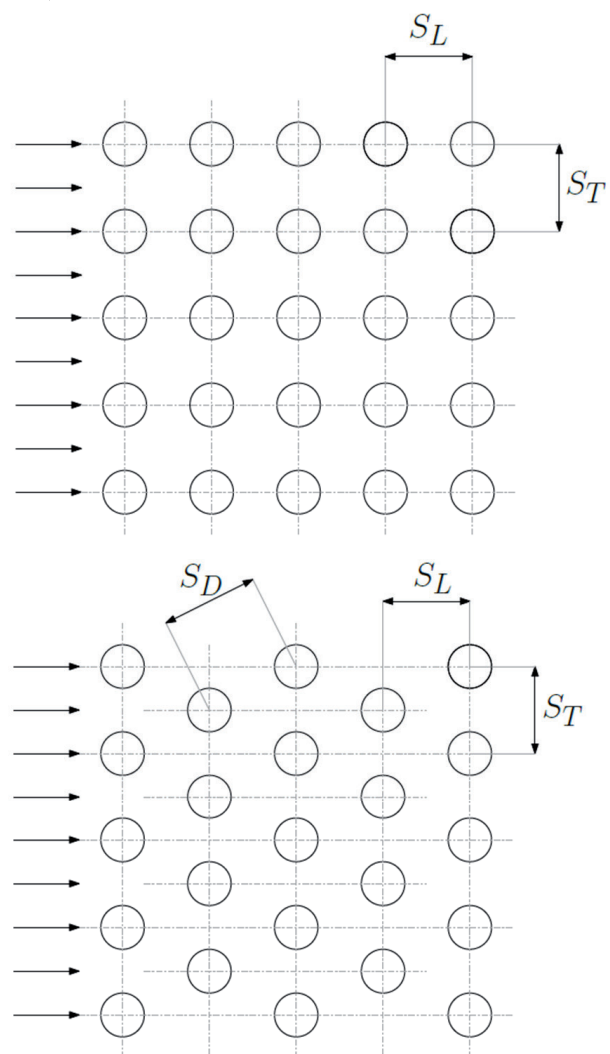

Figure 2: In-line arrangement (on left) and staggered arrangement (on right). 
The first studies on pressure drop appeared at the beginning of the last century. Among the first were Grimison [11] and Jakob [12]. The next [13], which was criticized shortly after publishing. All those models are not used nowadays. Kays and London improved Grimison model [14]. Žukauskas work [15] was one of the most extensive and we can find his model in many handbooks [16], [17]. These two models, unfortunately, have the pressure drop coefficient given in form of tables or graphs only for the most common pitches $(1.25,1.5,2.0,2.5)$. In the case of Zukauskas, the data for typical Reynolds numbers of PHFHE are missing.

In VDI-Heat Atlas [18] the model, which is based mostly on Gnieliski and does not have these obstacles, is published. This model is used in the presented study:

$\Delta p=\xi n_{r} \frac{\rho v_{\max }^{2}}{2}$,

where $\xi$ is pressure drop coefficient, $n_{r}$ number of rows, $v_{\max }$ velocity in the narrowest cross-section a $\rho$ is the fluid density. The pressure drop coefficient is the function of the arrangement (inline vs. staggered), unidimensional pitches and Reynolds number:

$\xi=\xi_{\text {lam }} f_{z, l}+\xi_{\text {turb }} f_{z, t} F$.

where $\xi_{\text {lam }}$ is laminar flow drag coefficient, $\xi_{\text {turb }}$ turbulent drag coefficient and $F$ coefficient dependent on the Reynolds number. The $f_{z, l}$ and $f_{z, t}$ are correction factors for temperature dependence of physical properties. All the above coefficients are different for the in-line and staggered arrangement and they are given explicitly as a function of arrangement non-dimensional pitches and Reynolds number, see [19].

\section{Experimental details}

The data of this study is taken from [9]. Two PHFHE with different fibre outer diameter, 0.6 and $0.8 \mathrm{~mm}$, called P3 and P4 respectively, but same pitches $\left(S_{T}=1.8 \mathrm{~mm}, S_{L}=2 \mathrm{~mm}\right)$ and number of rows (14 rows) were tested in certified calorimetric circuit. The precision of the measurement is in the range of $\pm 3 \%$. Inside the fibres flowed $50 / 50 \%$ water-glycol coolant solution, temperature $60{ }^{\circ} \mathrm{C}$. As a cooling medium, the $20^{\circ} \mathrm{C}$ air was used. The measurements were done for 1, 2, 4 and $10 \mathrm{~m} / \mathrm{s}$ air speed.
Due to the extruding technology and tiny dimension of the fibre, the tolerance of the diameter of hollow fibre was usually $\pm 10 \%$ in both directions, therefore the computation was done for the nominal diameter as for the $10 \%$ bigger and $10 \%$ smaller diameter. The flexibility of hollow fibres and manufacturing processes cannot guarantee that the arrangement will be precisely in-line as is intended and designed for those heat exchangers. Therefore, the study is done for both arrangements.

\section{Results and Discussion}

Firstly, we can compare the measured pressure drop of the two PHFHE. Those differs in the fibre diameter. The P4 has bigger diameter and obtained higher values of the pressure drop, around $25 \%$ more than P3. In the Fig. there is pressure drop plotted against the heat rejection. The heat rejection is similar for both PHFHE.

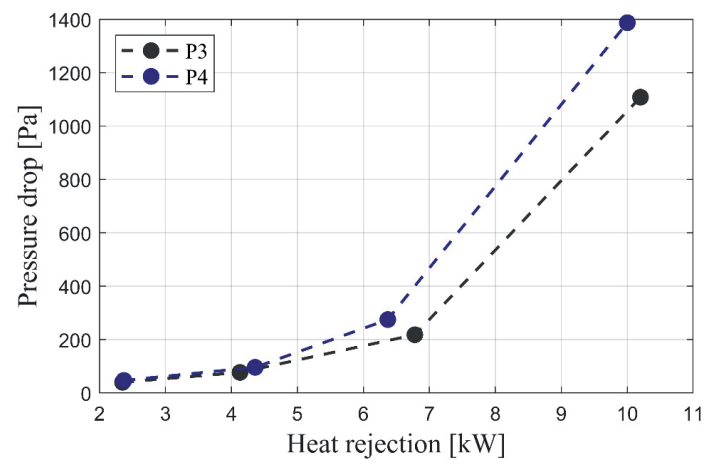

Figure 3: Pressure drop of PHFHE on the Heat rejection.

The measured pressure drop for two PHFHE were compared to the computed values, that was calculated for both arrangement, inline and staggered. In both arrangements, the calculation was done with the nominal value of diameter as well as with values that are $10 \%$ higher/lower. The results are plotted in the Fig. 3.

In Fig. 4. it can be seen that the measured values of pressure drop are much higher than those computed. In lower air speed the relative error is even high as $458 \%$ for P3 and $280 \%$ for P4. With increasing air speed the relative error decrease but it is still quite high. For $10 \mathrm{~m} / \mathrm{s}$ air speed prediction for P3 is having $118 \%$ relative error and P4 $51 \%$.

The variation of diameter causes very significant variation in the pressure drop, namely for P3 it is + $20 \%$ and $-15 \%$ and for P4 up to $+32 \%$ and $-23 \%$. 

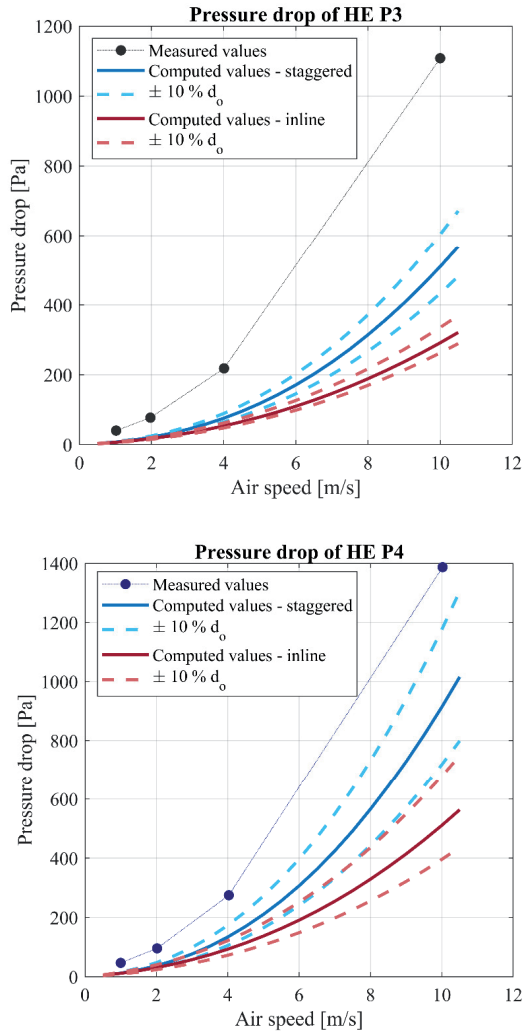

Figure 4: The results.

The relative error remains almost the same in all air speed range. Absolutely the difference between the smallest and the largest diameter can be even 200 $\mathrm{Pa}$ (in case of air speed $10 \mathrm{~m} / \mathrm{s}$ ).

The discrepancy of the measured and computed results is caused by the flexibility of the polymeric hollow fibre. Firstly, due to the flexibility, the pitches are not the same in the whole heat exchanger and changes with the air flow. The other cause is flowinduced vibrations. The equations used are derived from experiments with metallic tubes, which are more rigid. The flexible fibres are more allowed to vibrate. The pressure drop increase with increasing vibration intensity was studied [20] but for the aluminium fin-tube radiator.

\section{Conclusions}

Polymeric hollow fibre heat exchangers are alternatives to conventional heat exchangers in applications where chemical resistance or low weight is needed. Along with the heat transfer rate, it is important to know the pressure drop of the heat exchanger, because the pumping power is related to the pressure drop. The optimization of the heat exchanger can save energy and economic cost. The present relations to approximate the pressure drop are in many cases inappropriate since are based on experiments with much bigger tubes and therefore the small Reynolds numbers are missing. The only model which can be used is having a large error. There is a need to revise those relations to the flexible fibres. The diameter of the fibre varies along its length, which can cause the inaccuracy in the pressure drop approximation. This inaccuracy can be even as large as $30 \%$ for common $10 \%$ variation in outer diameter. This has to be taken into account when designing the PHFHE.

\section{Acknowledgments}

This work was supported by the Ministry of Education, Youth and Sports of the Czech Republic under OP RDE grant number CZ.02. 1.01/0.0/0.0/16_019/0000753 „Research centre for low-carbon energy technologies".

\section{References and Notes}

[1] Chen, X., Su, Y., Reay, D. and Riffat, S. (2016) Recent Research Developments in Polymer Heat Exchangers - A Review. Renewable and Sustainable Energy Reviews, 60, pp. 13671386.

[2] Zarkadas, D. M. and Sirkar K. K. (2004) Polymeric Hollow Fibre Heat Exchangers. Industrial and Engineering Chemistry Research. 43, 25, pp. 8093-8106.

[3] Song, L., Li, B., Zarkadas, D., Christian, S. and Sirkar K. K. (2010) Polymeric Hollow-Fibre Heat Exchangers for Thermal Desalination Processes. Industrial and Engineering Chemistry Research. 49, 23, pp. 11961-11977.

[4] Song, S., Shan, H., Liu, J., and Li, B. (2018) Heat Transfer Study of PVDF Hollow Fibre Heat Exchanger for Desalination Process. Desalination. 446, pp. 1-11.

[5] Raudensky, M., Astrouski, I., and Dohnal, M. (2017) Intensification of Heat Transfer of Polymeric Hollow Fibre Heat Exchangers by Chaotisation. Applied Thermal Engineering. 113, pp. 632-638.

[6] Weiß, K., Astrouski, I., Reppich, M. and Raudenský, M. (2018) Polymeric Hollow-Fibre Bundles as Immersed Heat Exchangers. Chemical Engineering \& Technology. 41, 7, pp. 1457-1465.

[7] Astrouski, I. and Raudensky M. (2014) Polymeric Hollow Fibre Heat Exchangers: Liquid-to-Gas Application. ASHRAE Transactions, 120, 2, pp. 95-105.

[8] Krasny, I., Astrouski, I. and Raudensky, M. (2016) Polymeric Hollow Fibre Heat Exhanger as an Automotive Radiator. Applied Thermal Enfineering. 108, pp. 798-803. 
[9] Idelchik, I. E. Handbook of Hydraulic Resistance.

[10] Grimison, E. (1937) Correlation and Utilization of New Data on Flow Resistance and Heat Transfer for Cross Flow of Gases over Tube Banks. Transactions of ASME. 59, pp. 583594.

[11] Jakob, M. (1938) Heat Transfer and Flow Resistance in Cross Flow of Gases over Tube Bank. Transactions of ASME. 60, pp 384.

[12] Gunter, A.Y. and Shaw, W. A. (1946) A General Correlation of Friction Factors of Various Types of Surfaces in Cross Flow. Transaction of ASME. 67, pp. 643-660.

[13] Kays, W.M. and London A.L. (1998) Compact Heat Exchangers. Krieger Pub. Co., Malabar.

[14] Zhukauskas, A. (1972) Heat Transfer from Tubes in Crossflow in Advances in Heat Transfer. Academic Press. Pp 93-158.

[15] Kakaç, S., Liu, H. and Pramuanjaroenkij, A. (2002) Heat Exchangers: Selection, Ration, and Thermal Design. CRC Press.

[16] Bergman, T. L., Incropera F. P., Dewitt D. P. and Lavine A. S. (2011) Fundamentals of Heat and Mass Transfer. John Wiley \& Sons, Inc., Noboken.

[17] Gaddis, E. S. (2010) Pressure Drop of Tube Bundles in Cross Flow. VDI-Heat Atlas. Pp. 1079-1091

[18] Li, D., Yang, X., Wang, S., Duan, D., Wan, Z., Xia, G., and Liu, W. (2020) Experimntal Research on Vibration-Enhanced Heat Transfer of Fin-Tube Vehicle Radiator. Applied Thermal Engineering. 180, pp. 115836.

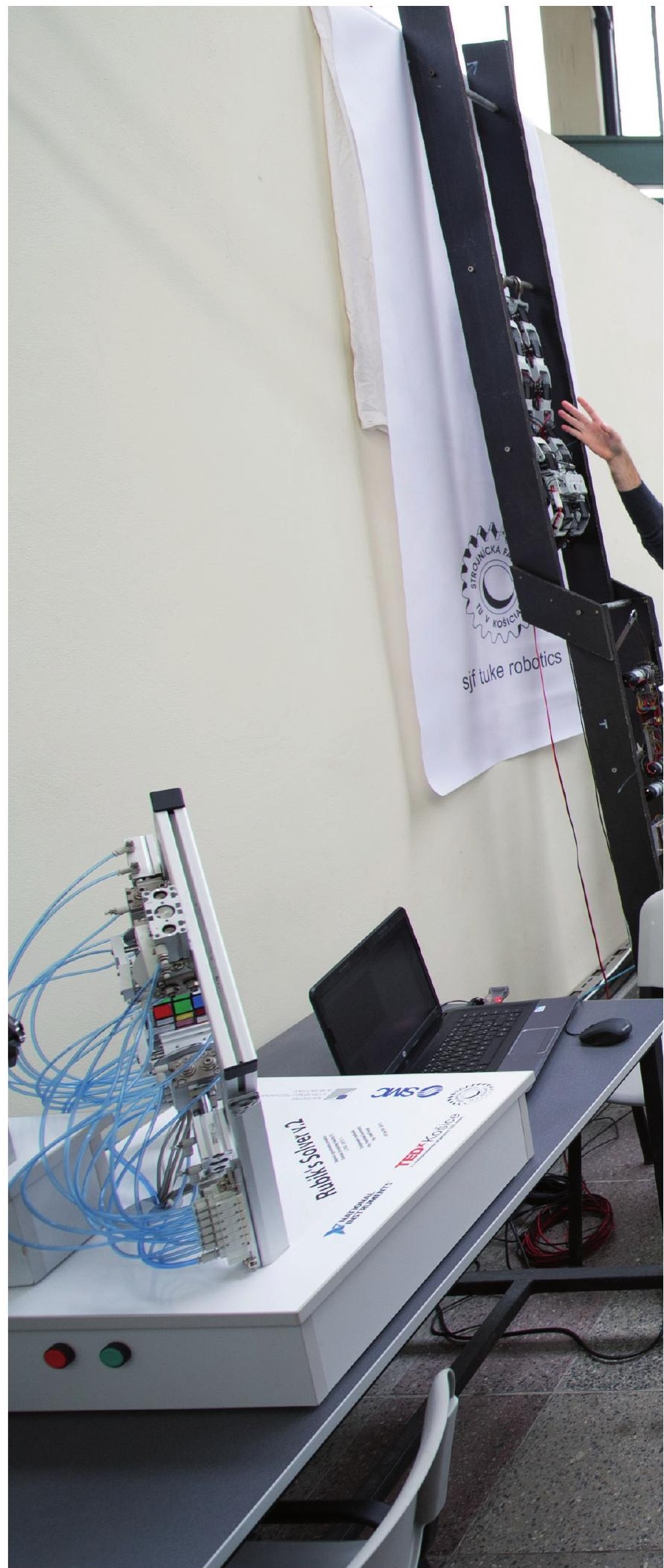

